\title{
A reforma trabalhista e a liquidez das relações de trabalho
}

\author{
Labor reform and the liquidity of relationships of job \\ LEONARDO BRANDALISE Machado \\ Universidade Federal de Rondônia
}

RESUMo O presente artigo tem como objetivo analisar como a reforma trabalhista, aprovada no Brasil por meio da Lei Ordinária 13467/2017, atua como legitimadora para que as relações de trabalho se tornem cada vez mais líquidas. A partir da leitura das obras de Bauman enumeramos as principais características da sociedade pós-moderna e líquida como a mudança da ética do produtor para a do consumidor, a perca da capacidade do trabalho de dar identidade ao ser humano, e também analisamos aspectos históricos que levaram o mundo a sair de seu estágio sólido para o líquido. Diante de tais características, analisamos as alterações promovidas pela recente reforma do direito do trabalho e verificamos que ela veio para legitimar uma nova forma de pensar nas relações laborais defendidas pelo modelo de capitalismo neoliberal na qual predomina a mentalidade de curto prazo e a falta de identidade do trabalhador com a empresa. Por fim, concluímos que apesar de necessária a reforma das leis trabalhistas, esta deveria ser feita com o intuito de defender o trabalhador, tendo em vista ser uma relação entre pessoas e não entre sujeito e objeto, levando em conta os direitos humanos e que possibilitasse a emancipação da sociedade em relação ao capital. Palavras-chave: Modernidade líquida; Reforma trabalhista; Relações de TrabaLHO.

ABSTRACT This article aims to analyze how the labor reform approved in Brazil through the Law of Provisions 13467/2017 acts as legitimating for labor relations to become increasingly liquid. From the reading of Bauman's works, we have listed the main characteristics of postmodern and liquid society, such as the change of the producer's ethics to the consumer, the loss of the capacity of the work to give identity to the human being, and also analyze historical aspects that led the world emerging from its solid stage into the liquid. Faced with such characteristics we analyzed the changes promoted by the recent labor reform and we verified that it came to legitimize a new way to think about labor relations defended by the model of neoliberal capitalism, which predominates the short-term mentality and the worker's lack of identity with the company. Finally, we concluded that, although it is necessary to reform the labor laws, it should be done with the intention of defending the worker bear in mind be a relation of persons and not between subject and object, taking into account human rights and enabling the emancipation of society from capital.

KeYwords: Liquid MODERnity; LABOR REFORM; Work Relationships. 


\section{INTRODUÇÃo}

A presente pesquisa parte do ponto de vista de que o conhecimento jurídico, como qualquer outra disciplina, é construído de maneira mais efetiva por meio da multidisciplinaridade.

A adequada hermenêutica sobre o momento em que se vive e as suas principais características são de extrema importância para que o direito seja aplicado da maneira mais correta possível.

Uma das concepções da vida pós-moderna é a ideia da liquidez de conceitos e relações. No âmbito do trabalho, existe a ideia de trabalhador descartável que parece descrever perfeitamente a realidade atual das relações de trabalho.

Temos como fatores típicos das relações de empregos dos tempos atuais um alto ritmo de trabalho, a alta competitividade e o medo do desemprego.

Trabalhamos com a hipótese de que a reforma trabalhista (PL 6787/2016 Transformado na Lei Ordinária 13467/2017) proposta pelo presidente Michel Temer em 23/12/2016 possa dar maior legitimação que as relações de trabalho se tornem cada vez mais líquidas.

O contrato de trabalho intermitente, a possibilidade de se prevalecer a negociação sobre a lei em diversos pontos, a diminuição dos poderes conferidos aos sindicatos, o aumento das facilidades da rescisão contratual e a regulamentação do Home Office são claramente pontos que vem a calhar com a nova forma de se ver as relações de trabalhos caracterizadas pela fluidez.

Assim, o direito que deveria ter o condão de fornecer segurança ao trabalhador tem feito exatamente o contrário ao sucumbir ao interesse do capitalismo neoliberal em sua forma mais selvagem e líquida, aumentando ainda mais a insegurança e incerteza dos trabalhadores, diminuindo a proteção contra a rescisão contratual sem justa causa e enfraquecendo a possibilidade de lutas coletivas por meio dos sindicatos, fatos que justificam a elaboração do presente trabalho.

O objetivo da presente pesquisa é entender como e por que as alterações propostas pela reforma trabalhista dão maior legitimação para que as relações de trabalho na pós-modernidade se tornem cada vez mais líquidas.

A pesquisa a ser realizada neste trabalho pode ser classificada como bibliográfica. Quanto à metodologia, o trabalho em mãos faz a opção pelo método histórico-hermenêutico. Enquanto procedimento, este trabalho realizar-se-á por meio de revisão bibliográfica.

\section{DA LIQUIDEZ DO MUNDO MODERNO}

\section{Aspectos históricos e conceituais da passagem da modernidade para a pós-modernidade}

A pós-modernidade nasceu da consciência do fracasso da modernidade e gerou um momento no qual os valores e conceitos típicos da era moderna passam a ser questionados, pois a humanidade perdeu a fé no homem moderno e seus conceitos.

A modernidade influenciada pelo iluminismo tinha como um dos seus principais valores a fé no espírito científico, a esperança de que a ciência levaria o mundo a um estado de eterno equilíbrio, paz e de que resolveria todos os problemas da humanidade. 
Assim, para romper com tamanha esperança, era necessário um episódio histórico sem precedentes para retirar a fé da humanidade em si, para romper com o espírito científico moderno e que retirasse a certeza de quais seriam os passos do progresso.

Tal episódio se materializou no evento do Holocausto, pois segundo Bauman (1998, p. 23) "a mensagem de que o Holocausto foi um fracasso, não um produto, da modernidade". Tal constatação foi feita a partir do momento em que foi percebido que a perpetuação do holocausto só foi possível devido ao uso de conceitos típicos da modernidade como burocracia, uso de tecnologia para diminuir custos e aumentar a produção, entre outros:

[...] o Holocausto foi tanto um produto como um fracasso da civilização moderna. Como tudo o mais que se faça à maneira moderna — racional, planejada, cientificamente fundamentada, especializada, eficientemente coordenada e executada - o Holocausto superou e esmagou todos os seus supostos equivalentes pré-modernos, expondo-os comparativamente como primitivos, perdulários e ineficientes. (BAUMAN, 1988, p. 112).

Fato é que o holocausto não pode ser considerado um evento apenas judeu e da Alemanha nazista, mas sim de toda a humanidade em seu período moderno, colocando em xeque, assim, os conceitos influenciadores da modernidade:

O Holocausto não foi simplesmente um problema judeu nem fato da história judaica apenas. O Holocausto nasceu e foi executado na nossa sociedade moderna e racional, em nosso alto estágio de civilização e no auge do desenvolvimento cultural humano, e por essa razão é um problema dessa sociedade, dessa civilização e cultura (BAUMAN, 1988, p. 12).

Pois, há de ser descartada a possibilidade de que o holocausto foi perpetuado por assassinos sanguinários ou psicopatas sem nenhuma capacidade de empatia pelas suas vítimas, só nos resta aceitar que os perpetuadores do grande genocídio nazista eram pessoas comuns como todas as outras e que estavam apenas obedecendo ordens:

\footnotetext{
'Vocês não ficariam mais felizes se eu pudesse mostrar que todos os que perpetraram [o crime] eram loucos?' - pergunta o grande historiador do Holocausto, Raul Hilberg. Mas é exatamente isso que ele não pode mostrar. A verdade que ele de fato mostra não traz nenhum alívio, é improvável que deixe alguém feliz. Os criminosos foram pessoas educadas de sua época. Esta é a questão crucial sempre que indagamos o significado da Civilização Ocidental depois de Auschwitz. (BAUMAN, 1988, p. 106).
}

O holocausto teve o papel de fazer com que a humanidade olhasse para os conceitos de progresso da modernidade de outra maneira, visto que um genocídio de tais proporções somente seria possível em meio a diversos conceitos típicos dos tempos modernos como a burocracia e o uso da ciência e racionalidade para alcançar melhores resultados.

Do questionamento de vários dos valores modernos, afinal tais valores contribuíram para o maior genocídio da história da humanidade, nasce o tempo chamado de pós-modernidade caracterizado pela liquidez ou fluidez, nesses tempos nada é feito para durar, o qual 
é marcado pela interrupção, incoerência, volatilidade como bem formulado na assertiva de Paul Valéry::

\begin{abstract}
Interrupção, incoerência, surpresa são as condições comuns de nossa vida. Elas se tornaram mesmo necessidades reais para muitas pessoas, cujas mentes deixaram de ser alimentadas por outra coisa que não mudanças repentinas e estímulos constantemente renovados... Não podemos mais tolerar o que dura. Não sabemos mais fazer com que o tédio dê frutos. Assim, toda a questão se reduz a isto: pode a mente humana dominar o que a mente humana criou? (apud BAUMAN, 2001, p. 7).
\end{abstract}

Com a noção de progresso da modernidade sendo desmantelada pelas duas guerras e principalmente pelo holocausto os movimentos do mundo pós-moderno se tornaram difícil de prever, pois se não há um norte a seguir é difícil distinguir o movimento certo a se fazer nesse momento.

Assim, na pós-modernidade, conforme Bauman (1998, não sabemos onde é "para frente" e onde é "para trás", e desse modo não podemos dizer com absoluta convicção qual movimento é "progressivo" e qual é "regressivo". Diante da falta de um norte a seguir e de conceitos bem definidos a liquidez passou a ser uma das maiores características dos tempos atuais.

Os fluídos podem ser descritos como os que não podem suportar uma força tangencial ou deformante quando imóveis. Ou seja, eles não têm densidade suficiente para manter a sua forma quando atingido por alguma força externa, adaptando-se conforme o recipiente em que é colocado.

Assim, pode-se entender que na modernidade sólida as coisas eram feitas para durar, os conceitos eram estáticos, plausíveis e de fáceis definições. Enquanto na modernidade líquida as coisas não são feitas para durar, conceitos são relativos, nada é simples de se definir.

\title{
A COSMOVISÃo do MUNDo PELA ÓTICA DA MODERNIDAde líquida
}

A modernidade líquida causou várias mudanças na forma de se ver, pensar e interpretar o mundo, sendo necessário examinar algumas dessas alterações para melhor entender a relevância do nosso trabalho.

\section{A ética do consumidor}

Com o advento da pós-modernidade houve uma ruptura com a ética do produtor e passou a predominar a ética do consumidor.

Bauman (2001) define a ética do consumo como um buffet no qual o consumidor é o responsável individualmente por proceder as melhores escolhas, definir prioridades e abandonar opções menos interessantes. A angústia, dessa forma, advém do excesso de opções e não de sua escassez.

$\mathrm{Na}$ ética do consumidor a responsabilidade de formular a identidade cabe somente ao próprio indivíduo e a mais nada ou ninguém. Instituições como o trabalho, a religião, o en- 
gajamento político, entre outras que eram responsáveis por ajudar a formular a identidade dos homens, perderam a relevância.

Dessa forma, Bauman (1998 nos adverte que na sociedade dos consumidores a identidade individual é construída solitariamente e, assim, impera uma incerteza absoluta, pois ela nunca se dá por completa, sendo necessário construí-la e desmanchá-la o tempo inteiro. Portanto, não há mais espaço para a reflexão ontológica.

Dessa maneira, resta apenas ao ser humano concentrar todas as suas forças na construção da própria identidade que no mundo pós-moderno é construída principalmente com base nas escolhas do "consumidor", por meio das compras feitas pelo indivíduo:

Vamos às compras pelas habilidades necessárias a nosso sustento e pelos meios de convencer nossos possíveis empregadores de que as temos; pelo tipo de imagem que gostaríamos de vestir e por modos de fazer com que os outros acreditem que somos o que vestimos; por maneiras de fazer novos amigos que queremos e de nos desfazer dos que não mais queremos; pelos modos de atrair atenção e de nos escondermos do escrutínio; pelos meios de extrair mais satisfação do amor e pelos meios de evitar nossa "dependência" do parceiro amado ou amante; pelos modos de obter o amor do amado e o modo menos custoso de acabar com uma união quando o amor desapareceu e a relação deixou de agradar; pelo melhor meio de poupar dinheiro para um futuro incerto e o modo mais conveniente de gastar dinheiro antes de ganhá-lo; pelos recursos para fazer mais rápido o que temos que fazer e por coisas para fazer a fim de encher o tempo então disponível; pelas comidas mais deliciosas e pela dieta mais eficaz para eliminar as consequências de comê-las; pelos mais poderosos sistemas de som e as melhores pílulas contra a dor de cabeça. A lista de compras não tem fim. Porém por mais longa que seja a lista, a opção de não ir às compras não figura nela. E a competência mais necessária em nosso mundo de fins ostensivamente infinitos é a de quem vai às compras hábil e infatigavelmente. (BAUMAN, 2001, p. 95-96).

Posto isso, no mundo pós-moderno, toda a vida é organizada em torno do consumo e as regras do jogo do consumidor são os desejos sempre crescentes e a comparação universal em vez da local.

Assim, a tendência da vida na modernidade líquida é a de total desregulamentação, uma vez que os desejos mudam a cada dia e as pessoas mais próximas não mais oferecem padrões de sucesso, visto que hoje é possível se comparar com o resto do mundo apenas com um celular por meio das redes sociais.

Percebemos, então, que "Na corrida dos consumidores, a linha de chegada sempre se move mais veloz que o mais veloz dos corredores; mas a maioria dos corredores na pista tem músculos muito flácidos e pulmões muito pequenos para correr velozmente" (BAUMAN, 2001, p. 94).

Ademais, podemos concluir que na modernidade líquida, em virtude de uma ética voltada ao consumidor, há uma extrema individualização que dificulta a possibilidade de políticas públicas realmente efetivas devido à certa colonização da esfera pública pela privada sobre a qual dissertaremos no próximo ponto. 


\title{
A COLONIZAÇÃo da ESFERA PÚblica PELA PRIVAdA
}

Como produto da ética dos consumidores podemos observar a existência de uma colonização da esfera pública pela privada, pois na ótica de vida pós-moderna a vida passou a ser pensada de maneira individual e não mais coletiva. Assim, o público passou a ser privatizado, os problemas que antes eram coletivamente resolvidos passaram à esfera pessoal.

Hoje há um volume enorme de discursos de "coachings", livros de autoajuda ou mesmo populares discursos de televisão ou "youtubers" nos quais é pregada a solução individualizada de conflitos que muitas vezes são sistematicamente construídos. Como Baumannos adverte:

\begin{abstract}
E, no entanto, se ficam doentes, supõe-se que foi porque não foram suficientemente decididos e industriosos para seguir seus tratamentos; se ficam desempregados, foi porque não aprenderam a passar por uma entrevista, ou porque não se esforçaram o suficiente para encontrar trabalho ou porque são, pura e simplesmente, avessos ao trabalho; se não estão seguros sobre as perspectivas de carreira e se agoniam sobre o futuro, é porque não são suficientemente bons em fazer amigos e influenciar pessoas e deixaram de aprender e dominar, como deveriam, as artes da autoexpressão e da impressão que causam. Isto é, em todo caso, o que lhes é dito hoje, e aquilo em que passaram a acreditar, de modo que agora se comportam como se essa fosse a verdade. (BAUMAN, 2001, p. 47-48).
\end{abstract}

Beck (1995 apud BAUMAN, 2001, p. 48) resume de forma espetacular tal privatização da resolução de conflitos sistêmicos: "a maneira como se vive torna-se uma solução biográfica das contradições sistêmicas. Riscos e contradições continuam a ser socialmente produzidos; são apenas o dever e a necessidade de enfrentá-los que estão sendo individualizados.”.

Desse modo, a política que antes pensávamos ter como função traduzir os problemas privados para questões de políticas públicas perdeu sua função e passou apenas a ser um acessório à vida privada. E o que está sendo cada vez mais visto como "público" são as questões privadas de pessoas públicas.

Pois como afirma Bauman (2001, p. 91) "A consequência que pode ser considerada mais interessante é o desaparecimento da 'política como a conhecemos' - da Política com P maiúsculo, a atividade encarregada de traduzir problemas privados em questões públicas". E "Não há mais seguro coletivo contra os riscos: a tarefa de lidar com os riscos coletivamente produzidos foi privatizada." (BAUMAN, 1998, p. 52).

Portanto, o que temos nos dias atuais é uma política inefetiva em relação à vida do indivíduo, visto que está limitada em suas ações em virtude da liberdade individual que nada mais é do que a individualidade levada ao extremo na pós-modernidade.

\section{Do CAPITALISMO SÓLIDO PARA O LÍQUIDO E SEUS EFEITOS NAS RELAÇÕES DE TRABALHO}

O capitalismo sólido, típico da modernidade na qual as coisas eram feitas para durar, era obcecado por volume e tamanho. Capital, administração e trabalho eram completamen- 
te interligados entre si. Para isso, era necessária uma supervisão constante, de ditadores de leis e cumpridores da mesma, de projetistas e executores de projeto.

O que dominava no capitalismo sólido era o estilo fordista de produção que era caracterizado por princípios como unidade de comando, divisão de trabalho acentuada, definição clara de responsabilidade, disciplina e autoridade.

Assim Bauman) define o capitalismo pesado como:

O capitalismo pesado, no estilo fordista, era o mundo dos que ditavam as leis, dos projetistas de rotinas e dos supervisores; o mundo de homens e mulheres dirigidos por outros, buscando fins determinados por outros, do modo determinado por outros. Por essa razão era também o mundo das autoridades: de líderes que sabiam mais e de professores que ensinavam a proceder melhor. (BAUMAN, 1988, p. 83).

O Fordismo era a grande marca do Capitalismo em sua fase sólida, pois era fonte de conceito que norteavam a vida do cidadão moderno.

As fábricas na modernidade sólida eram como grandes fortalezas que necessitavam de defensores e de mão de obra qualificada para mantê-las em seu pleno funcionamento sendo Henry Ford o grande responsável por descobrir como manter os trabalhadores dentro de seu castelo industrial:

O gênio de Henry Ford foi descobrir o modo de manter os defensores de sua fortaleza industrial dentro dos muros - para guardá-los da tentação de desertar ou mudar de lado. Como disse o economista da Sorbonne Daniel Cohen: Henry Ford decidiu um dia "dobrar" os salários de seus trabalhadores. A razão (publicamente) declarada, a célebre frase "quero que meus trabalhadores sejam pagos suficientemente bem para comprar meus carros" foi, obviamente, uma brincadeira. As compras dos trabalhadores eram uma fração ínfima de suas vendas, mas os salários pesavam muito mais em seus custos... A verdadeira razão para o aumento dos salários foi a formidável rotatividade de força de trabalho que a Ford enfrentava. Ele decidiu dar o aumento espetacular aos trabalhadores para fixá-los à linha (BAUMAN, 2001, p. 75-76).

Desse modo, podemos dizer que o capitalismo em sua fase sólida se preocupava em manter os trabalhadores fixados na linha de produção, em manter uma rotina de trabalho fixa, uma divisão de trabalho extremamente acentuada e principalmente uma intensa supervisão dos empregados para que eles obedecessem a ordens anteriormente definidas.

Já o capitalismo em sua fase líquida os valores não estão mais necessariamente ligados ao volume e tamanho como eram na fase sólida. Por exemplo, podemos citar que recentemente a Netflix ultrapassou a Disney, dona de imenso patrimônio físico, em valor no bolsa de valores americanas.

Tal fenômeno é explicado pela atual descorporificação do capital, fazendo com que ele flua leve e intensamente:

Vivemos agora uma outra "grande transformação": e um de seus aspectos mais visíveis é um fenômeno que é o exato oposto da condição que Polanyi supunha: 
a "descorporificação" daquele tipo de trabalho humano que serve como principal fonte de nutrição, ou campo de pastagem, para o capital contemporâneo. Instalações de vigilância e treinamento la Panóptico, volumosas, confusas e desajeitadas, não são mais necessárias, $\mathrm{O}$ trabalho foi libertado do Panóptico, mas, o que é mais importante, o capital se livrou do peso e dos custos exorbitantes de mantê-lo; o capital ficou livre da tarefa que o prendia e o forçava ao enfrentamento direto com os agentes explorados em nome de sua reprodução e engrandecimento (BAUMAN, 2001, p. 153-154).

Assim, o capitalismo se desfez de suas amarras e hoje flui levemente acarretando grandes impactos na vida dos indivíduos que devem lidar com as consequências de tais mudanças.

\section{A MUdanÇa no PaRADigma da AUTORIDAde}

Uma primeira mudança advinda com o capitalismo em sua forma liquefeita foi a questão da autoridade. Desse modo, o que se vê na modernidade líquida não é a desfeita total de qualquer autoridade, mas o aumento do seu número fazendo com que elas se anulem entre si:

O capitalismo leve, amigável com o consumidor, não aboliu as autoridades que ditam leis, nem as tornou dispensáveis. Apenas deu lugar e permitiu que coexistissem autoridades em número tão grande que nenhuma poderia se manter por muito tempo e menos ainda atingir a posição de exclusividade. Ao contrário do erro, a verdade é só uma, e pode ser reconhecida como verdade (isto é, com o direito de declarar erradas todas as alternativas a ela mesma) justamente por ser única. Parando para pensar, "numerosas autoridades" é uma contradição em termos. Quando as autoridades são muitas, tendem a cancelar-se mutuamente, e a única autoridade efetiva na área é a que pode escolher entre elas. E por cortesia de quem escolhe que a autoridade se torna uma autoridade. As autoridades não mais ordenam; elas se tornam agradáveis a quem escolhe; tentam e seduzem (BAUMAN, 2001, p. 83).

Outra mudança importante a ser considerada se dá em torno da nova técnica de poder utilizada na pós-modernidade que são o desengajamento e a arte da fuga. O Poder que antes era confrontado pelo engajamento coletivo passou a reinar sozinho sem nenhuma interferência que lhe deixasse acuado ou temeroso.

Bauman propõe o engajamento coletivo talvez como o principal remédio contra as novas formas de poder protagonizadas pelo novo capital:

Quem sabe não seria um remédio manter-se, como no passado, ombro a ombro e marchar unidos? Quem sabe se, caso os poderes individuais, tão frágeis e impotentes isoladamente, fossem condensados em posições e ações coletivas, poderíamos realizar em conjunto o que ninguém poderia realizar sozinho? Quem sabe... O problema é, porém, que essa convergência e condensação das queixas individuais em interesses compartilhados, e depois em ação conjunta, é uma tarefa assustadora, dado que as aflições mais comuns dos "indivíduos por fatalidade" nos dias de hoje são não- aditivas, não podem ser "somadas" numa “causa comum' Podem ser postas lado a lado, mas não se fundirão. Pode-se di- 
zer que desde o começo são moldadas de tal maneira que lhes faltam interfaces para combinar-se com os problemas das demais pessoas. (2001, p. 48-49)

Dessa forma, percebemos que na ética do consumidor, na qual o engajamento coletivo torna-se praticamente inexistente e que as questões de política pública foram colonizadas pela esfera privada, torna-se difícil a união de pessoas em busca de melhores condições de vida para todos.

\section{O TRABALHO SEM ADEREÇOS ESCATOLÓGICOS}

Outra mudança importante que ocorreu na passagem do capitalismo em sua fase sólida para a líquida foi o fato de o trabalho ter perdido alguns de seus adereços que gozava na modernidade como ser o agente regulador da ordem e atividade laboral, ser a tarefa em que toda humanidade está (por vontade própria ou alheia) envolvida:

Quaisquer que tenham sido as virtudes que fizeram o trabalho ser elevado ao posto de principal valor dos tempos modernos, sua maravilhosa, quase mágica, capacidade de dar forma ao informe e duração ao transitório certamente está entre elas. Graças a essa capacidade, foi atribuído ao trabalho um papel principal, mesmo decisivo, na moderna ambição de submeter, encilhar e colonizar o futuro, a fim de substituir o caos pela ordem e a contingência pela previsível (e portanto controlável) sequência dos eventos. Ao trabalho foram atribuídas muitas virtudes e efeitos benéficos, como, por exemplo, o aumento da riqueza e a eliminação da miséria; mas subjacente a todos os méritos atribuídos estava sua suposta contribuição para o estabelecimento da ordem, para o ato histórico de colocar a espécie humana no comando de seu próprio destino. [...] O "trabalho" assim compreendido era a atividade em que se supunha que a humanidade como um todo estava envolvida por seu destino e natureza, e não por escolha, ao fazer história. E o "trabalho" assim definido era um esforço coletivo de que cada membro da espécie humana tinha que participar. O resto não passava de consequência: colocar o trabalho como «condição natural» dos seres humanos, e estar sem trabalho como anormalidade; denunciar o afastamento dessa condição natural como causa da pobreza e da miséria, da privação e da depravação; ordenar homens e mulheres de acordo com o suposto valor da contribuição de seu trabalho ao empreendimento da espécie como um todo; e atribuir ao trabalho o primeiro lugar entre as atividades humanas, por levar ao aperfeiçoamento moral e à elevação geral dos padrões éticos da sociedade (BAUMAN, 2001, p. 172-173).

Já na sua forma leve e liquefeita o trabalho se tornou apenas um instrumento para que o ser humano possa se ocupar na atividade em que todos estão hoje realmente envolvidos (por vontade própria ou alheia) que é o consumo.

Outra atribuição que foi perdida pelo trabalho na era do capitalismo leve é a sua capacidade de gerar definições para o indivíduo e de constituir um projeto de vida para a vida do cidadão.

Tais atividades passaram a ser prioritariamente pelo consumidor como visto anteriormente (a ética do consumidor): 


\begin{abstract}
Despido de seus adereços escatológicos e arrancado de suas raízes metafísicas, o trabalho perdeu a centralidade que se lhe atribuía na galáxia dos valores dominantes na era da modernidade sólida e do capitalismo pesado. $\mathrm{O}$ trabalho não pode mais oferecer o eixo seguro em torno do qual envolver e fixar auto definições, identidades e projetos de vida. Nem pode ser concebido com facilidade como fundamento ético da sociedade, ou como eixo ético da vida individual (BAUMAN, 2001, p. 175).
\end{abstract}

Concluímos, assim, que na fase do capitalismo sólido, que foi marcado pelas grandes fábricas, indústrias automobilísticas e estradas de ferro, a acumulação de capital era diretamente ligada ao seu tamanho e volume.

Dessa maneira, para proteger o capital era necessário um funcionamento parecido com o das grandes fortalezas da antiguidade que tinha como necessidade manter os súditos fiéis e engajados na manutenção do grande "castelo".

Mas na sua fase líquida o capital não está mais ligado ao seu tamanho ou volume, ele flui livre e levemente independente de qualquer amarra, não necessitando de mão de obra fiel, assim podendo se desfazer dela sempre quando for preciso e sem oponentes que possam questionar o poder e sua dominação devido ao predominante desengajamento coletivo.

\title{
AS RELAÇÕES DE TRABALHO EM TEMPOS PÓS-MODERNOS
}

Diante de todo exposto acima, foi desenvolvido um novo tipo de relação de emprego que tem como característica um alto ritmo de trabalho, a alta competitividade e um constante medo do desemprego.

\section{O DIREITO DO TRABALHO NA CONCEPÇÃO DO CAPITALISMO NEOLIBERAL}

Para melhor entendermos as relações de trabalho no modelo de capitalismo neoliberal devemos nos atentar aos princípios de orientação econômica que regem a nossa sociedade pós-moderna. Segundo Polanyi, existem quatro princípios de integração econômica:

a) o de mercado, no qual ocorre o encontro entre a oferta e a procura de bens e serviços, tendo como fim a troca, sendo ajustada por meio do preço, que utiliza a moeda como forma geral de equivalência; b) o de redistribuição, em que a produção é direcionada a uma autoridade central, incumbida de armazená-la e, posteriormente, distribuí-la; c) o de reciprocidade, em que uma pessoa oferece qualquer coisa a outra pessoa e esta retribui qualquer coisa à primeira, e esta oferenda de "dádivas" tem um importante efeito social, pois tem por fundamento que os objetos não são dissociados de quem os oferece, representando, essencialmente, um comportamento social; e d) o da domesticidade, que consiste na produção para consumo próprio - é a produção e o armazenamento para satisfazer às necessidades de determinado grupo (POLANYI, 1980. P 60)

Atualmente vivemos sob a vigência do modelo de integração econômico de mercado, fato que tem enorme impacto sobre a vida da sociedade, pois o mercado passa a preponderar em virtude da comunidade. 
Dessa maneira, o mercado acaba por reger e regulamentar a vida em sociedade que necessita se adaptar ao modelo de integração econômica vigente para ter meios de subsistência.

O direito do trabalho entendido sob a visão do capitalismo neoliberal, o qual defende a liberação do mercado até às últimas consequências, propõe que o desenvolvimento econômico só é possível por meio da desregulamentação total do direito do trabalho, permitindo-se a livre flexibilização/desregulamentação das relações laborais e, assim, um retrocesso jurídico e social.

Na concepção do capitalismo neoliberal é necessário um direito do trabalho que venha a dar legitimidade para o processo de demissão constante nas empresas ou para uma mão de obra desarraigada e descompromissada por meio de empregos temporários e intermitentes:

\begin{abstract}
No processo de downsizing, as empresas norte-americanas do capitalismo neoliberal criaram uma força de trabalho contingente, composta por empregados que, involuntariamente, tiveram de se submeter a trabalhar como trabalhadores em tempo parcial, trabalhadores temporários, trabalhadores com contrato por prazo limitado e consultores "autônomos". Trata-se de empregados regulares dispensados, que tiveram de se sujeitar a trabalhar por salários muito mais baixos daqueles anteriormente recebidos (CASTELO, 2003, p.152).
\end{abstract}

Tal fato também é atestado por Bauman):

As empresas começam a "enxugar" seus quadros. Diante desta situação, o
estado moral e a motivação dos trabalhadores caem vertiginosamente. E, no
lugar de vibrarem com a manutenção dos empregos, os trabalhadores que
sobrevivem "aos cortes" somente esperam pelo novo golpe de foice. (BAU-
MAN, 2001, p. 139-140)

Assim, a finalidade do direito do trabalho deveria ser a de assegurar a melhoria da condição social do trabalhador, tendo como princípio fundamental o protetor. A partir desse princípio o direito trabalhista deve ser um conjunto de princípios, normas e instituições que tenham por objeto a melhoria da condição social do trabalhador e o proteja da selvageria do capitalismo neoliberal.

Conforme Castelo (2017, p. 82) "É tarefa do direito trabalhista valorizar o direito humano do trabalhador no patamar da liberdade pessoal de configurar a relação de trabalho; mais uma vez, como uma relação de direito da pessoa".

Concluímos que os direitos trabalhistas deveriam partir do ponto de vista de que servem para regular uma relação entre dois sujeitos e não uma entre sujeito e objeto, pois se trata de um direito que envolve pessoas.

Ademais, o direito do trabalho teria o escopo de direitos humanos e não poderia haver retrocessos, pois é por meio dele que pode ocorrer a emancipação da sociedade em face do mercado e assim se promova a verdadeira liberdade e se cumpra com o princípio da dignidade humana. 


\section{O ADOECIMENTO DO TRABALHADOR EM VIRTUDE DA FALTA DE ESTABILIDADE NO AMBIENTE LABORAL}

Temos como características típicas da relação de trabalho pós-moderna a intensificação do ritmo de trabalho, a diversificação das atividades e a polivalência funcional como atributo de competência, o medo e a apreensão pela demissão a qualquer momento.

Tais características causam o adoecimento do trabalhador conforme vários estudos efetivados no Brasil e no mundo. No Brasil, segundo dados oferecidos pela OPAS (Organização Pan-Americana da Saúde) foi feito um estudo sobre afastamento devido a acidentes e doenças ocupacionais e se descobriu que $14 \%$ dos benefícios anuais de saúde foram relacionados a transtornos mentais.

Entre 2009 e 2015, segundo dados da OMS (Organização Mundial da Saúde), quase 97 mil pessoas foram aposentadas por invalidez em razão de transtornos mentais e comportamentais, com destaque para depressão, distúrbios de ansiedade e estresse pós-traumático.

Segundo Dados do INSS de todo o pessoal afastado no ano de 2016 devido a transtornos de comportamento em geral, ao menos 10,6 mil tiveram o ambiente profissional como um dos agentes desencadeadores da doença.

Nos Estados Unidos da América, que têm o modelo neoliberal de legislação trabalhista, há um grande número de trabalhadores que estão adoecendo tanto na parte física como na psicológica devido às características das relações de trabalhos pregadas pelos teóricos do neoliberalismo:

\footnotetext{
A estimativa norte-americana, de acordo com Timms (2006), revela que 30\% dos trabalhadores terão algum acometimento em saúde mental a cada ano, sendo a depressão um dos mais comuns. $\mathrm{O}$ autor sinaliza que o adoecimento mental desencadeia comprometimento do rendimento no trabalho, ocasionando elevação do quadro de absenteísmo por doença, acidentes de trabalho e rotatividade de pessoal. O empregado acometido por depressão poderá apresentar, segundo o autor, elevada taxa de erros nas tarefas, dificuldade de concentração, incapacidade de delegar tarefas, lentidão, execução das atividades com intenso sofrimento psíquico, atrasos em compromissos, entre outros (SILVA et al., 2009, p. 85).
}

E segundo a Organização Mundial da saúde (1996), a depressão será em 2020 o principal motivo de perda de trabalho no mundo e também a maior causa da incapacidade laboral.

\section{DOS COMPONENTES NECESSÁRIOS PARA O BEM-ESTAR NO AMBIENTE DE TRABALHO}

Para combater o adoecimento do trabalhador é necessária uma concepção do que seria um ambiente de trabalho saudável que, segundo Siqueira e Padovam (2008), leve em conta principalmente os três componentes a seguir: satisfação no trabalho, envolvimento com o trabalho e comprometimento organizacional afetivo.

Satisfação no trabalho é "[...] um estado emocional positivo ou de prazer, resultante de um trabalho ou de experiências de trabalho." (LOCKE, 1976, p. 1300 apud SIQUEIRA; PA- 
DOVAM, 2008, p. 206). Já envolvimento com trabalho é "[...] grau em que o desempenho de uma pessoa no trabalho afeta sua autoestima" (LODAHL; KEJNER, 1965, p. 25 apud SIQUEIRA; PADOVAM, 2008, p. 206) e comprometimento organizacional afetivo é "“...] um estado no qual um indivíduo se identifica com uma organização particular e com seus objetivos, desejando manter-se afiliado a ela com vista a realizar tais objetivos." (MOWDAY; STEERS; PORTER, 1979, p. 225 apud SIQUEIRA; PADOVAM, 2008, p. 206).

Diante dos conceitos expostos acima verificamos que o modelo de trabalho na pós-modernidade não é capaz de promover melhor bem-estar junto ao trabalhador, pois o que impera nas relações trabalhistas neoliberais é a mentalidade de curto prazo, com a descorporificação do trabalhador e o medo constante da demissão, fatores que colaboram com o adoecimento do trabalhador.

\section{DAS ALTERAÇÕES PROMOVIDAS PELA REFORMA TRABALHISTA E A LEGITIMAÇÃO PARA MAIOR LIQUIDEZ DAS RELAÇÕES DE TRABALHO}

Trabalhamos com a hipótese de que a reforma trabalhista (PL 6787/2016 Transformado na Lei Ordinária 13467/2017) proposta pelo presidente Michel Temer em 23/12/2016 daria maior legitimação para que as relações de trabalho se tornem cada vez mais líquidas.

Assim, analisaremos algumas alterações promovidas pela reforma nos atentando principalmente aos que teriam o condão de legitimar o modelo de capitalismo neoliberal e as relações de trabalho em sua forma liquefeita.

Talvez as principais alterações que mais se adequaram à proposta do direito do trabalho líquido foram: a) A regulamentação do teletrabalho; b) A criação do contrato de trabalho intermitente; c) Da possibilidade da terceirização irrestrita; d) As propostas que enfraquecem a figura dos sindicatos de trabalhadores; e) Da possibilidade de o acordado prevalecer sobre o legislado; f) $\mathrm{O}$ aumento das facilidades da rescisão contratual.

\section{DA REgUlamentaÇÃo do TELETRABalHo}

A reforma trabalhista entre outras alterações acarretou na regulamentação do teletrabalho, mais conhecido como home office, o que está previsto nos arts. 75-A ao 75-E. Tal forma de trabalho surgiu devido às novas tecnologias que possibilitaram uma visualização dos acontecimentos do mundo inteiro em tempo real criando uma cultura da informação:

\footnotetext{
O teletrabalho, consoante prega o sociólogo Domenico De Masi (2000), pode constituir-se em importante instrumento não só para a realização profissional, mas para a integração e harmonização deste para com os demais direitos de cidadania. Nesse contexto, verifica-se que as origens do teletrabalho foram pensadas como forma de dar ênfase à responsabilidade social das empresas, pensando o trabalho dentro de um contexto mais contemporâneo, realizável com menor impacto ao meio ambiente urbano, menor gasto de energia, combustíveis e utilizando-se das novas tecnologias. (BERTOLLO, 2018, p. 79).
}

Mas o que se vê quando se trata do cenário brasileiro talvez seja justamente o contrário. Pois a regularização dessa forma de emprego parece estar sendo muito mais uma forma 
de precarização do teletrabalho do que uma forma de manutenção e aprimoramento dos direitos sociais conquistados.

O Capítulo II-A da CLT aborda o conceito do teletrabalho e direciona regras contratuais ao âmbito negocial entre patrão e empregado. Mas o inciso III do artigo 62 da nova CLT excepciona os teletrabalhadores do pagamento de horas extraordinárias e demais regras contidas no capítulo referente à duração do trabalho resultando, assim, em um grande prejuízo ao empregado em regime de home office.

$\mathrm{O}$ argumento de que no teletrabalho não há possibilidade de fiscalização das horas' trabalhadas pelo funcionário é descabível, visto que segundo Castelo "Um trabalhador em flexitempo controla o local de trabalho, mas não adquire maior controle sobre o processo do trabalho em si." (2017, p. 60) e "Atualmente, vários estudos já indicam que a supervisão, fiscalização e controle do trabalho praticado com relação aos empregados é, na verdade, maior para os ausentes do escritório do que para os presentes." (CASTELO, 2017, p.60).

Assim segundo Bertollo:

[...] pouco se vislumbra em termos de garantias legais (e isonômicas) ao trabalhador remoto, sendo que o tratamento do teletrabalho na nova CLT segue a linha inspiradora dos novos valores liberais consagrados pela reforma trabalhista. [...] Nesse escopo, abalizados juristas subscrevem que o trabalho informal, despido de garantias sociais historicamente conquistadas, não constitui incremento do emprego e não proporciona crescimento econômico, limitando-se a afrontar direitos constitucionais de solidariedade. (BERTOLLO, 2018. P. 75).

Nesse sentido, verificamos que apesar de ser necessária a regulamentação do home office, os termos em que foi aprovado acaba por se adequar à forma de trabalho predominante na era pós-moderna e do capitalismo neoliberal.

\section{DO CONTRATO DE TRABALHO INTERMITENTE}

$\mathrm{O}$ contrato de trabalho intermitente encontra-se previsto no artigo 452-A. Tal modalidade de contrato previsto pela da nova legislação trabalhista, autoriza e regulamenta a realização de trabalhos esporádicos de um determinado profissional para uma determinada empresa, sem a necessidade de rotina e jornada fixa:

Art. 452-A. O contrato de trabalho intermitente deve ser celebrado por escrito e deve conter especificamente o valor da hora de trabalho, que não pode ser inferior ao valor horário do salário mínimo ou àquele devido aos demais empregados do estabelecimento que exerçam a mesma função em contrato intermitente ou não (BRASIL, 1943).

Com isso, o empregador está autorizado a formalizar vínculos de trabalho somente quando achar necessário, convocando pessoas que já têm contrato de forma antecipada, no momento que necessitar de mais mão de obra. Segundo o art. 452-A a remuneração será pré-definida com base no valor da hora de trabalho, a qual não pode ser inferior ao salário mínimo vigente. 
Tal forma de contrato de trabalho não agrega nenhuma segurança ao empregado que não sabe quando será chamado pelo empregador para prestar serviços, assim não há garantia nenhuma de que terá alguma remuneração a seu favor em determinados meses do ano.

Além disso, o contrato de trabalho intermitente não produz a identificação do empregado com a empresa contratante e isso dificulta a possibilidade de luta por melhores condições de trabalho, pois não há nenhuma identificação com os trabalhadores fixos ou com a própria firma.

Assim, percebemos que o contrato de trabalho intermitente vem a calhar com o modelo de capitalismo neoliberal e líquido ao dificultar na possibilidade de identificação do empregador com a firma e promover o desengajamento e a arte da fuga que são as novas formas de domínio do capitalismo moderno.

\section{DA POSSIBILIDADE DA TERCEIRIZAÇÃO IRRESTRITA}

O Projeto de Lei n. ${ }^{\circ} 4.302 / 98$, alterou dispositivos da Lei n. ${ }^{\circ}$ 6.019/1974 que tratam do trabalho temporário em empresas urbanas e dispõe sobre as relações de trabalho nas empresas de prestação de serviços a terceiros. O referido projeto foi sancionado tornando-se a Lei 13.429/2017.

O objetivo principal desse projeto seria permitir a descentralização do trabalho em todos os níveis e em todos os setores, tanto nas atividades-meio como nas atividades-fim, tornando externos os custos e riscos.

Dessa forma, o art. $4^{\circ}$ da Lei 13.467/17 substituiu a redação anterior da Lei 13.429/17 e determina que:

\footnotetext{
Considera-se prestação de serviços a terceiros a transferência feita pela contratante da execução de quaisquer de suas atividades, inclusive sua atividade principal, à pessoa jurídica de direito privado prestadora de serviços que possua capacidade econômica compatível com a sua execução (BRASIL, 1943).
}

Com base em tal texto podemos perceber uma grande descorporificação do trabalho, possibilitando que até mesmo a mão de obra da atividade-fim seja terceirizada. Tendo, dessa maneira, como terceirizar todas as atividades da empresa.

Tal forma de trabalho,segundo Miraglia e Oliveira:

[...] mitiga o poder de resistência dos trabalhadores e a consciência de classe, além de intensificar a vulnerabilidade e a exploração física e psíquica.

A possibilidade de terceirizar as atividades empresariais de forma irrestrita, expulsando da planta empresarial inclusive as atividades essenciais relacionadas ao fim do empreendimento, potencializa a capacidade de exploração do trabalho e, ao mesmo tempo, reduz a possibilidade de o empregado reaver seus direitos. Isso porque, a empresa tomadora responde apenas de forma subsidiária pelas verbas trabalhistas inadimplidas pela empresa terceirizada, ainda que tenha sido ela a real e principal beneficiária do trabalho humano(MIRAGLIA E OLIVEIRA, 2018, p. 86). 
Ademais, concluímos que a irrestrita terceirização é extremamente importante na agenda do capitalismo neoliberal, visto que liberta o empregador da contratação direta de funcionários e dificulta um engajamento por parte dos trabalhadores que não conseguem desenvolver um sentimento de pertencimento à mesma classe trabalhadora.

\section{DO ENFRAQUECIMENTO DOS SINDICATOS}

A reforma trabalhista modificou o art. 579 da CLT que ressaltava a obrigatoriedade da contribuição sindical nos seguintes termos:

Art. 579 - A contribuição sindical é devida por todos aqueles que participarem de uma determinada categoria econômica ou profissional, ou de uma profissão liberal, em favor do sindicato representativo da mesma categoria ou profissão ou, inexistindo este, na conformidade do disposto no art. 591 (BRASIL, 1943).

Que passou a vigorar da seguinte maneira:

Art. 579. O desconto da contribuição sindical está condicionado à autorização prévia e expressa dos que participarem de uma determinada categoria econômica ou profissional, ou de uma profissão liberal, em favor do sindicato representativo da mesma categoria ou profissão ou, inexistindo este, na conformidade do disposto no art. 591 desta Consolidação (BRASIL, 1943).

O que percebemos com a alteração do texto trabalhista é que foi instituído à desobrigatoriedade da contribuição sindical, sendo facultativo ao trabalhador a contribuição ao sindicato.

A consequência que vemos da desobrigatoriedade da contribuição sindical é uma grande perda da força sindical. Segundo dados do MTE, as entidades sindicais tiveram uma queda de $88 \%$ de arrecadação nos quatro primeiros meses do ano, fato que comprova o enfraquecimento dos sindicatos após o advento da reforma trabalhista.

O que percebemos é que na pós-modernidade, tempo no qual se prevalece a individualidade e a ética do consumo, não há nenhum interesse do trabalhador em contribuir com as entidades sindicais por vontade própria, sendo necessária contribuição obrigatória para que o sindicato tenha recursos para dar ao trabalhador o suporte necessário na conquista de direitos.

Dessa maneira, as forças do capitalismo neoliberal podem reinar sem nenhum concorrente social capaz de oferecer resistência. E sem um concorrente social, o capitalismo não é forçado a incluir os excluídos, perpetuando-se a desigualdade.

\section{DA POSSIBILIDADE DO ACORDADO PREVALECER SOBRE O LEGISLADO}

A reforma trabalhista apresenta a possibilidade de a negociação coletiva de trabalho prevalecer sobre a lei em diversos pontos, conforme o Art. 611-A da CLT que dispõe o seguinte:

Art. 611-A. A convenção coletiva e o acordo coletivo de trabalho têm prevalência sobre a lei quando, entre outros, dispuserem sobre:

I - pacto quanto à jornada de trabalho, observados os limites constitucionais; 
II - banco de horas anual;

III - intervalo intrajornada, respeitado o limite mínimo de trinta minutos para jornadas superiores a seis horas; [...] (BRASIL, 1943).

Percebemos que as negociações coletivas de trabalho ganharam grande importância, visto que as suas negociações, em diversos pontos, poderão prevalecer sobre a própria lei.

Apesar de defender a importância dos sindicatos de trabalhadores e que ele deve ter força suficiente para confrontar os empregadores, há de se convir que existem muitos sindicatos que não defendem verdadeiramente o trabalhador e que em muitas vezes têm mais identificação com o empresário do que com o próprio empregado.

Tendo em vista o enfraquecimento do sindicato que não tem mais a contribuição sindical obrigatória a seu favor, percebemos que nesses pontos nos quais há possibilidade de o negociado prevalecer ao disposto em lei, deve-se sobressair o interesse do capitalismo neoliberal, tornando o direito mais desregulamentado e líquido.

\section{O AUMENTO DAS FACILIDADES DA RESCISÃO CONTRATUAL}

A reforma trabalhista também tem em seu texto alterações que facilitaram a rescisão contratual. O primeiro exemplo está contido na nova possibilidade de extinção contratual por meio do acordo entre empregado e empregador que está previsto no art. 484-A da CLT, in verbis:

Art. 484-A. O contrato de trabalho poderá ser extinto por acordo entre empregado e empregador, caso em que serão devidas as seguintes verbas trabalhistas: (Incluído pela Lei $n^{\circ} 13.467$, de 2017)

I - por metade: (Incluído pela Lei no 13.467, de 2017)

a) o aviso prévio, se indenizado; e (Incluído pela Lei n ${ }^{\circ} 13.467$, de 2017)

b) a indenização sobre o saldo do Fundo de Garantia do Tempo de Serviço, prevista no $\S 1$ o do art. 18 da Lei no 8.036, de 11 de maio de 1990; (Incluído pela Lei $n^{\circ} 13.467$, de 2017)

II - na integralidade, as demais verbas trabalhistas. (Incluído pela Lei n ${ }^{\circ} 13.467$, de 2017)

$\S 1^{\circ}$ A extinção do contrato prevista no caput deste artigo permite a movimentação da conta vinculada do trabalhador no Fundo de Garantia do Tempo de Serviço na forma do inciso I-A do art. 20 da Lei no 8.036, de 11 de maio de 1990, limitada até $80 \%$ (oitenta por cento) do valor dos depósitos. (Incluído pela Lei $n^{\circ} 13.467$, de 2017)

$\S 2^{\circ}$ A extinção do contrato por acordo prevista no caput deste artigo não autoriza o ingresso no Programa de Seguro-Desemprego (BRASIL, 1943).

A rescisão contratual que antes tinha que ser homologada pelo sindicato da categoria ou pelo Ministério Público do Trabalho, agora pode ser diretamente negociada entre empregador e funcionário.

Tendo em vista que o princípio da proteção do trabalhador rege a CLT, percebemos que a alteração do texto da lei foi prejudicial à figura do empregado, o que em situação de hipossuficiência em relação ao patrão perde direitos ao aceitar, coagido pelo empregador, uma rescisão contratual que apenas teoricamente foi de comum acordo. 


\section{O DIREITO DO TRABALHO VISTO SOBRE O ESCOPO DOS DIREITOS HUMANOS}

O capitalismo em sua essência visa o lucro e devido a tal essência concordamos com a assertiva de Castelo (2003, p. 110) "Sem um concorrente social, o capitalismo não é forçado a incluir os excluídos.".

O direito trabalhista tem o condão de produzir emancipação do trabalhador em relação ao capital, produzir liberdade, e fazer com que o capital não reine absoluto na vida dos trabalhadores. Conforme nos afirma Castelo (2003, p. 182) "Os direitos trabalhistas traduzem-se, assim, em uma regulação social com vistas a objetivos emancipatórios, à procura de uma nova ética política e social ajustada aos novos tempos e aos novos ideais de igualdade/distribuição que possibilitem capacitação/emancipação.".

O direito do trabalho, se analisada a sua história, nasceu como um direito advindo do campo progressista:

\footnotetext{
O direito do trabalho inseriu-se, assim, no sistema jurídico, como ramo do direito pós-moderno, no qual a ousadia e a combatividade dos movimentos progressistas conseguiu impor normas de proteção aos trabalhadores, que, como hoje, representam a maioria da sociedade. Logo, representaram a emancipação social em face do mercado obtida através do espaço democrático, do espaço da cidadania CASTELO, 2003, p. 144-145).
}

Ademais, para se ter uma melhor garantia dos direitos concedidos aos trabalhadores é necessário que o direito material e o processual que permeiam as relações de trabalho sejam vistos como ramos ligados aos direitos humanos, pois eles não podem sofrer retrocessos ou serem limitados.

\section{Conclusão}

Diante de todo o exposto, concluímos que a reforma trabalhista que já está em vigor constitui em uma grande adaptação da CLT aos moldes do capitalismo neoliberal tornando as relações de trabalho mais líquidas e frágeis.

O que vimos na reforma foram diversas alterações que enfraquecem a força sindical, fragilizando o trabalhador que hipossuficiente em relação ao empregador (e em tempos de extremo desemprego) acaba por aceitar condições piores de trabalho.

Temos de ter a consciência da necessidade de modernização da legislação trabalhista, que não mais responde várias questões apresentadas pela pós-modernidade.

Porém, é essencial que a modernização da sociedade e do direito sejam feitas com o objetivo de promover emancipação social e não apenas para se adaptarem às exigências do capitalismo neoliberal, selvagem e líquido, o que não tem em seu modus operandi a inclusão dos excluídos ou qualquer forma de promover igualdade social.

Muitos pensadores da pós-modernidade tendem a agir e pensar como se o processo neoliberal fosse incontrolável, como se nada pudesse ser feito para resistir a ele. Restando apenas a opção de se submeter e se adaptar a esse novo paradigma de pensamento.

Entretanto, tal fato não será resolvido pelo capitalismo, mas sim pela democracia e 
pela humanidade, reunindo forças para combater o constante impulso de tornar cada vez mais líquidas as relações de trabalho.

Como solução para a problemática, propomos que o direito do trabalho seja pensado por meio do paradigma dos direitos humanos, levando em conta que as relações de trabalho são relações de pessoas e não de objetos.

Caso os direitos trabalhistas sejam produzidos como um meio de cidadania, o domínio da classe dominante nunca será total, se tornando um meio de emancipação da sociedade em face do mercado, fazendo da organização da lei laboral um grande sistema contra a precarização das condições de trabalho, típicas em uma pós-modernidade líquida.

\section{REFERÊNCIAS}

BAUMAN, Zygmunt. Modernidade Líquida. Rio de Janeiro: Zahar, 2001. 278 p.

BAUMAN, Zygmunt. Modernidade e Holocausto. Rio de Janeiro: Zahar, 1998. 206 p

BERTOLLO, Adriana B. Um olhar crítico sobre a regulamentação do teletrabalho na recente reforma trabalhista brasileira. Raizes Jurídicas, Curitiba, v. 10, n. 1, p. 71-83, jan. 2018. Disponível em: <http://ojs.up.com.br/index.php/raizesjuridicas/article/view/790/ pdf_53>. Acesso em: 27 set. 2018.

BRASIL. Decreto-Lei n. 5452, de 01 de maio de 1943. Consolidação das Leis do Trabalho. CLT. Rio de Janeiro, p. 1-151, jan. 1943. Disponível em: <http://www.planalto.gov.br/ccivil_03/Decreto-Lei/Del5452.htm>. Acesso em: 11 set. 2018.

CASTELO, Jorge P. O direito Material e Processual do Trabalho e a Pós-modernidade: A CLT, o CDC e as repercussões do Novo Código Civil. São Paulo: LTR, 2003. 424 p.

CASTELO, Jorge P. O direito do trabalho líquido: O negociado sobre o legislado, a terceirização e o contrato de curto prazo na sociedade da modernidade líquida. São Paulo: LTR, 2017. 91 p.

ESTRESSE no ambiente de trabalho cobra preço alto de individuos, empregadores e sociedade. 2016. Disponível em: $<$ https://www.paho.org/bra/index.php?option=com_content\&view $=$ article $\& \mathrm{id}=5087$ : estresse-no-ambiente-de-trabalho-cobra-preco-alto-de-individuos-empregadores-e-sociedade\&Itemid=839> . Acesso em: 28 maio 2018.

MAIS de 75 mil pessoas foram afastadas do trabalho por depressão em 2016: OMS alerta que, até 2020, mal será a doença mais incapacitante do mundo. 2017. Disponível em: $<$ https:/epocanegocios.globo.com/Carreira/noticia/2017/02/mais-de-75-mil-pessoas-foram-afastadas-do-trabalho-por-depressao-em-2016.html>. Acesso em: 28 maio 2018. 
MIRAGLIA, Livia Mendes Moreira; OLIVEIRA, Rayhanna Fernandes de Souza. A Reforma trabalhista e o trabalho escravo contemporâneo: análise dos impactos da terceirização irrestrita e da banalização do trabalho em sobrejornada. In: HERNANDEZ, Julianna do Nascimento; MIRAGLIA, Livia Mendes Moreira; OLIVEIRA, Rayhanna Fernandes de Souza (org.). Trabalho Escravo Contemporâneo: Conceituação, desafios e perspectivas. Rio de Janeiro: Lumen Juris, 2018. p. 83-101. Disponível em: https://pos.direito.ufmg. br/wp-content/uploads/colecao-ppgd-ufmg-2018/Trabalho\%20Escravo\%20Contempor\%C3\%A2neo-L\%C3\%ADvia\%20Miraglia-EB.pdf\#page=101. Acesso em: 15 nov. 2021.

POLANYI, K. A grande transformação. As origens da nossa época. Rio de Janeiro: Campus, 1980.

SILVA, Justino et al. Considerações sobre o transtorno depressivo no trabalho. Revista Brasileira de Saúde Ocupacional, São Paulo, v. 34, n. 119, p. 79-87, maio. 2009. Disponível em: <http://www.redalyc.org/html/1005/100512332009/>. Acesso em: 08 set. 2018.

SIQUEIRA, Mirlene M. M.; PADOVAM, Valquiria A. R.. Bases Teóricas de Bem-Estar Subjetivo, Bem-Estar Psicológico e Bem-Estar no Trabalho. Psicologia: Teoria e Pesquisa, São Paulo, v. 24, n. 2, p. 201-209, jan. 2008. Disponível em: <http://www.scielo.br/pdf/ ptp/v24n2/09>. Acesso em: 08 set. 2018.

\section{Leonardo Brandalise Machado}

Graduado em direito pela Faculdade de Rondônia (FARO). Mestre em Ética e Filosofia Política pela Universidade Federal de Rondônia (UNIR).

Submetido em: 11-2-2021

Aceito em: 26-3-2021 